Review

\title{
Don't scrap the waste: The need for broader system boundaries in bioplastic food packaging life-cycle assessment - A critical review
}

\author{
Sarah Kakadellis a, Zoe M. Harris a, b, * \\ ${ }^{a}$ Centre for Environmental Policy, Imperial College London, London, SW7 1NE, United Kingdom \\ ${ }^{\mathrm{b}}$ Centre for Environment and Sustainability, University of Surrey, Guildford, Surrey, GU2 7XH, United Kingdom
}

\section{A R T I C L E I N F O}

\section{Article history:}

Received 19 November 2019

Received in revised form

12 May 2020

Accepted 11 June 2020

Available online 16 July 2020

Handling Editor: Prof. Jiri Jaromir Klemeš

\section{Keywords:}

Bioplastic

Food waste

Life-cycle assessment

Plastic packaging

Systematic literature review

Waste management

\begin{abstract}
A B S T R A C T
The increasing amount of plastic waste generated each year, fuelled by the growing consumption of single-use plastics in food packaging applications, threatens the integrity of our ecosystems while creating an unprecedented waste management crisis. The biodegradable properties of some bioplastics have been identified as a promising solution to divert food and food packaging waste from landfill while avoiding plastic leaking into the environment. However, such bio-based biodegradable alternatives may not necessarily provide an improvement in overall environmental impact, especially when considering their efficacy at preventing food waste. This is the first systematic review to investigate the relationship between food packaging and food waste, based on conventional and biodegradable plastic food packaging life-cycle assessments (LCAs). It focuses on the trade-offs that may occur between food packaging production, end-of-life management and food waste prevention across the entire food packaging lifecycle. Following a review of 111 papers, 19 were identified for further investigation and data extraction. Quantitative analysis for five LCA impact categories, as well as hotspot analysis and end-of-life scenario analysis for global warming potential were conducted. The resulting picture is conflicting and suggests that though bioplastics display environmental benefits for global warming potential and nonrenewable energy use, these are often negated by the agricultural inputs required for bioplastics raw material production. While the LCAs included in this study do not provide enough evidence to state which polymer is best at reducing food waste, they emphasise the environmental footprint associated with food production and food waste, and highlight the importance of including the food itself in food packaging LCAs. Therefore, focusing on food packaging performance in food waste minimisation is critical. We found that bioplastics provide the benefit of diverting biodegradable waste from landfill or incineration to 'greener' streams such as anaerobic digestion and composting, contributing to a circular economy. Encouraging biodegradable bioplastics should target plastic packaging where effective recycling measures are failing due to the challenges that remain for treating and recycling materials made of multiple, highly food-contaminated layers. The bioplastic industry is still young and optimising both the manufacturing process and material biophysical properties would contribute towards improving the overall environmental profiles of bioplastics.
\end{abstract}

( $) 2020$ The Author(s). Published by Elsevier Ltd. This is an open access article under the CC BY license (http://creativecommons.org/licenses/by/4.0/).

\section{Contents}

1. Introduction

Abbreviations: AD, Anaerobic digestion; BBP, Biodegradable bio-based plastic; EoL, End-of-life; LCA, Life-cycle assessment; GHG, Greenhouse gas; GWP, Global warming potential; PLA, Polylactic acid.

* Corresponding author. Centre for Environment and Sustainability, Arthur C Clarke building, Floor 2, University of Surrey, Guildford, Surrey, GU2 7XH, United Kingdom.

E-mail addresses: sarah.kakadellis14@imperial.ac.uk (S. Kakadellis), z.harris@ surrey.ac.uk (Z.M. Harris). 


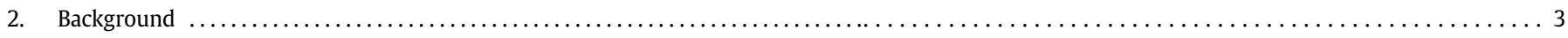

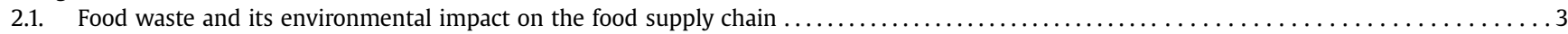

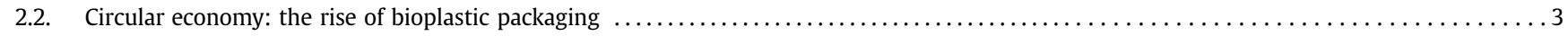

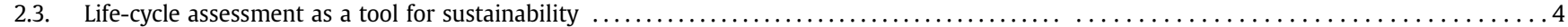

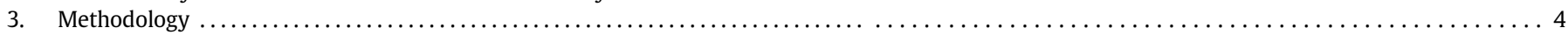

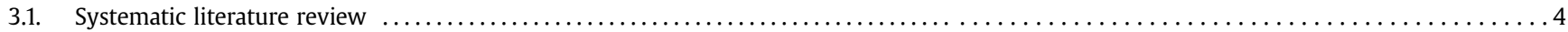

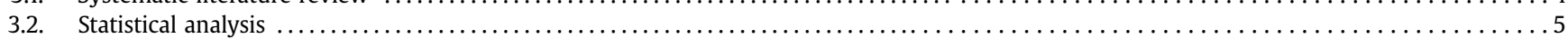

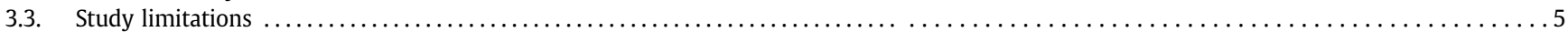

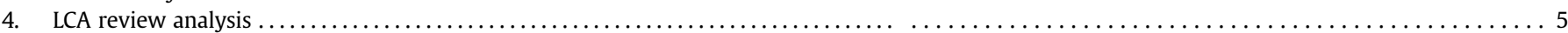

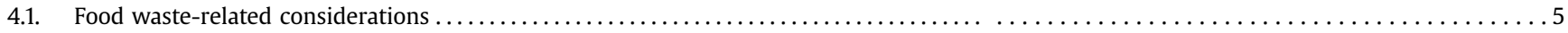

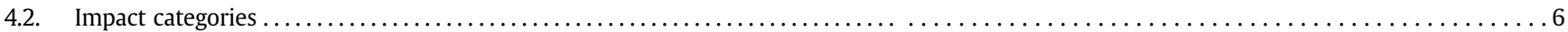

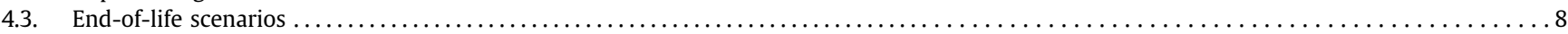

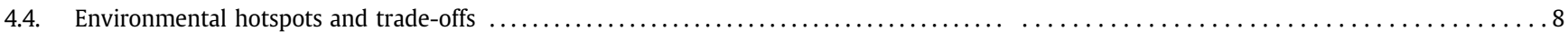

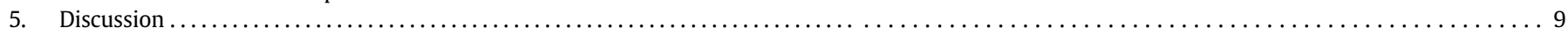

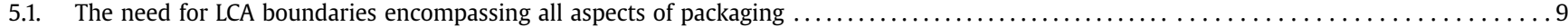

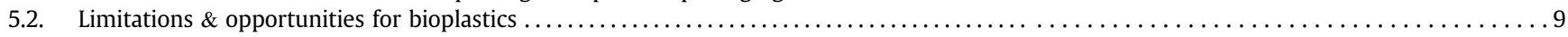

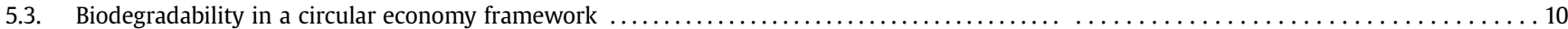

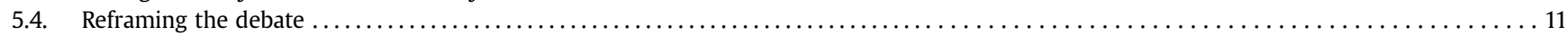

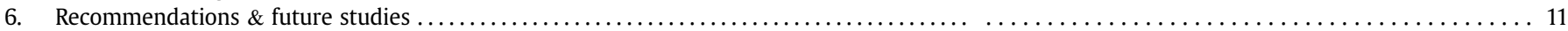

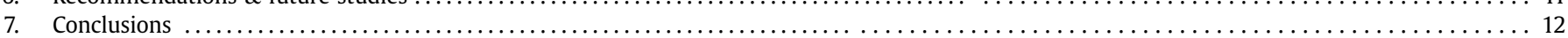

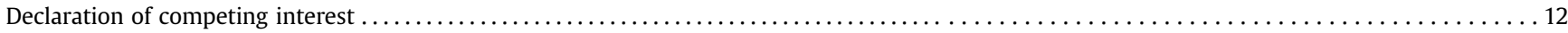

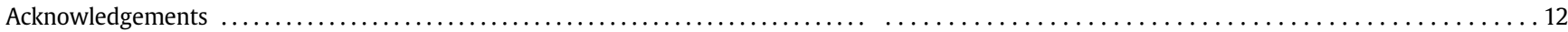

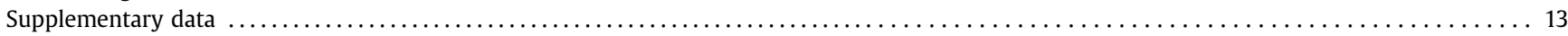

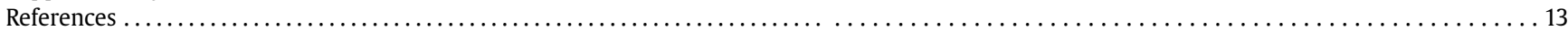

\section{Introduction}

In light of globalisation and consumerism, the shift to a 'throwaway' society has placed considerable strain on the planet's raw materials and resources. At the heart of this issue and of growing concern is the ever-increasing use of single-use plastic that underpins our 'disposable society'. As a result, we inevitably generate waste - no matter how we manage it, there is an environmental impact (HM Government, 2018). Plastic pollution is one of the most contentious issues to have come under public scrutiny, in part due to the success of the BBC's Blue Planet II series, which disseminated the reality of plastics leaking into our environment and the impacts of microplastics (Buranyi, 2018).

Packaging accounts for the largest application of plastics with $40 \%$ of the plastic market share (Plastics Europe, 2016). It is estimated that $41 \%$ of all packaging used in 2007 was food packaging (Muncke, 2009), most of which was made from plastics (Muncke, 2015). Packaging has revolutionised the entirety of the food supply chain. From the large array of food produce customers have gained access to throughout seasons and across geographic locations, to the way food is processed, transported and displayed, purchasing food has never been more convenient (Ellen MacArthur Foundation, 2019). With over half of the world population now living in cities, with projections reaching $68 \%$ by 2050 (UN, 2018), packaging ensures food quality is preserved throughout more complex and extended supply chains, from production to consumption (Advisory Committee on Packaging, 2008).

Single-use food and drink plastic packaging are amongst the most common items found in oceans and coastal surveys around the globe (Ocean Conservancy, 2017), posing a serious threat to the integrity of our ecosystems, while creating an unprecedented waste management problem. Both the European Union (EU) and the Unites States (US) have been promoting more circular approaches in waste management (EU, 2018; U.S. Chamber of Commerce Foundation, 2015).

The biodegradable properties of some bioplastics have been identified as an opportunity to address this societal and environmental challenge. They represent a solution for packaging applications by diverting plastics from landfills without persisting in the environment, particularly marine (EU, 2018). However, such biodegradable and bio-based alternatives may not necessarily provide an improvement in overall environmental impact (Narancic et al., 2018), especially when considering the functional aspects of packaging, such as end-of-life management, handling for transport and retailing, as well as waste reduction, including increasing shelf-life (Verghese et al., 2012). While Yates and Barlow (2013) and Hottle et al. (2013) have both reviewed bioplastic LCAs, a holistic assessment of their environmental impact in the context of food packaging, particularly around the role of packaging in minimising food waste, remains understudied.

This review project adopts a life-cycle perspective to address the sustainability of conventional oil-based plastics and biodegradable bio-based plastics (BBPs) in the field of food packaging. Though it focuses on the European policy framework, the implications are applicable to a global perspective. It intends to highlight both the opportunities and possible trade-offs within the food-packaging system and focuses on the relationship between food waste, food packaging and packaging waste. Using a systematic literature review of 19 previously published life-cycle assessments (LCAs), all stages from production and processing to transport and disposal at the end-of-life are investigated. A whole systems approach is important to ensure that the total environmental impact is considered when identifying new packaging (Wikström and Williams, 2010). The rationale for broader LCAs that take a wider approach - looking at both production of the packaging material as well as the agricultural inputs for the packaged food and food waste - is based on the existing research gap on the understanding of environmental impacts that consider food production and food waste (Molina-Besch et al., 2019; Verghese et al., 2014). To our knowledge, this is the first systematic review of LCAs on BBP food packaging addressing the environmental impact of food waste. 


\section{Background}

\subsection{Food waste and its environmental impact on the food supply chain}

Food security is an emerging challenge for governments and industry in the food supply chain (Verghese et al., 2013). As consumption patterns swell, driven by increased wealth and higher living standards, demand for abundant and nutritious food is peaking. Climate change, competing land uses, soil erosion and diminishing supplies of clean water are already threatening food production worldwide (Verghese et al., 2013). One of the potential solutions to this dilemma is enhanced efficiency and waste reduction across the food supply chain (Verghese et al., 2013).

Food wastage undermines the sustainability and efficiency of our current food supply chains, both in the developed and developing world. Households are throwing substantial amounts of edible food; globally 1.3 billion tonnes are wasted each year (FAO, 2011). The greenhouse gas (GHG) emissions generated by food waste globally represent the third largest emitter in the world, outstripped only by the US and China (FAO, 2019). Although recently plateauing, European household food waste levels are amongst the highest in the world, at $70 \mathrm{~kg}$ per capita per year (Schweitzer et al., 2018). In the United Kingdom (UK) alone, some 10.2 million tonnes (Mt) per year of post-farm gate food waste have been estimated, with about 70\% lost at the consumer level (Gillick and Quested, 2018).

Considering that the production, distribution and consumption of food produce is a major player in the environmental impacts of consumption in the EU, any measure to reduce food waste, even to a small extent, may have a significant effect on overall environmental footprint (Williams and Wikström, 2011). So far, the predominant focus has been on material use and recovery of packaging through recycling, while research on the role of packaging in food waste reduction has been overlooked (Williams et al., 2008). In addition, alternative end-of-life options that fit within a circular economy framework, such as industrial composting or anaerobic digestion, may provide environmental benefits through increasing the amount food waste available for biological processing (DilkesHoffman et al., 2018).

In 2015, guided by the United Nations (UN) 2030 Agenda for Sustainable Development, the EU launched the Circular Economy Action Plan with the ambition to deliver a climate-neutral economy within planetary boundaries and ensure cycling of natural and freshwater resources within a closed loop (EU, 2015). As the UK prepares to leave the EU, the UK government published their new Waste and Resources Strategy that follows the objectives of the Circular Economy Package, aiming to tackle the infamous issues of packaging and food waste (HM Government, 2018). In the US, the Environmental Protection Agency's Waste Reduction Model (WARM) provides a life-cycle tool that can be used to measure GHG reductions associated with food waste reduction, or alternative disposal methods (Heller et al., 2019).

\subsection{Circular economy: the rise of bioplastic packaging}

Most food packaging design, use and disposal methods are inconsistent with the objectives of the circular economy, underlined by low rates of reuse and recycling, as well as significant levels of leakage into the environment, particularly marine (Schweitzer et al., 2018). Plastic packaging remains highly challenging for waste management and the environment; in the EU, less than $30 \%$ of plastic waste is collected for recycling, with most of it being exported to Southeast Asia (Schweitzer et al., 2018). Low recycling rates stem from food contamination - particularly problematic for food packaging -, plastic fibre deterioration or lack of economic incentives for a low-value plastic market (Ross, 2019).

In this context, defining what constitutes a sustainable packaging becomes a critical task. Pauer et al. (2019) give the following definition: 'packaging that has to be effective, efficient and safe for human health and the environment' (p.1). Governmental coercive measures to limit fossil-based activities have favoured the development of a bioeconomy with a shift from fossil-based to bio-based plastics (Spierling et al., 2018).

Despite increasing attention, the term 'bioplastic' is commonly misunderstood due to the ever-growing number of alternative polymers emerging on the market and a lack of well-defined characteristics (Brockhaus et al., 2016). Bioplastics are not all made from one single material; they comprise a whole family of materials with differing feedstocks, properties and applications (European Bioplastics, 2016). The term 'bioplastic' encompasses two distinct concepts:

- Bio-based plastics: plastics (partly or fully) made from biological and renewable resources such as grains, starchy root vegetables, sugar cane or vegetable oils;

- Biodegradable: plastics that can be degraded by naturallyoccurring microorganisms into water, carbon dioxide $\left(\mathrm{CO}_{2}\right)$, methane $\left(\mathrm{CH}_{4}\right)$ and inorganic compounds under certain conditions. The process of biodegradation depends on the surrounding environmental conditions (e.g. location or temperature), on the material and on the application (European Bioplastics, 2016).

A plastic material is defined as a bioplastic if it is either biobased, biodegradable, or both (European Bioplastics, 2016; Plastics Europe, 2016). Fig. 1 provides a graphical visualisation according to the two concept axes. This review focuses on bioplastics that are both biodegradable and bio-based (top right quadrant), hereafter referred to as biodegradable bioplastics (BBPs), unless stated otherwise. The biodegradable properties of BBPs offer an unprecedented potential solution to divert food waste from landfills while also preventing plastic leaking into the environment. Yet switching from conventional, non-biodegradable plastics to BBP packaging does not necessarily indicate an improvement in overall sustainability. In the case of bioplastics, it is important to ensure

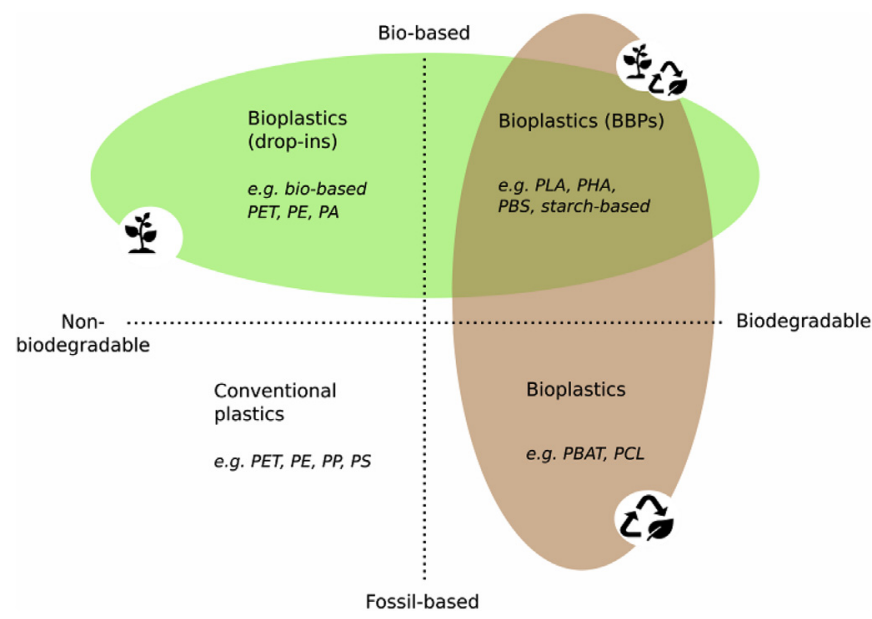

Fig. 1. Bioplastics: material origin and biodegradability properties. PE: Polyethylene; PET: Polyethylene Terephthalate; PA: Polyamide; PP: Polypropylene; PS: Polystyrene; PLA: Polylactic Acid; PHA: Polyhydroxyalkanoate; PBS: Polybutylene Succinate; PBAT: Polybutylene Adipate Terephthalate; PCL: Polycaprolactone. (Adapted from: European Bioplastics, 2016). 
that they provide genuine environmental benefits compared their non-renewable counterparts across their entire life-cycle (EU, 2016).

\subsection{Life-cycle assessment as a tool for sustainability}

LCA is a framework that can be used to assess the environmental impacts of a product throughout its lifespan, from the production stage to end-of-life disposal (Yates and Barlow, 2013). An LCA involves collecting information on the inputs and outputs, such as emissions, waste, and resources, of a process (life-cycle inventory) and translating those to environmental impacts, using standardised impact assessment methodologies (ISO 14040:2006). Fig. 2 shows the typical flow diagram of a cradle-to-grave LCA for both conventional (a) and bioplastic packaging (b).

For oil-based plastics, stages of crude oil extraction and refining are considered, while for bio-based, agricultural inputs for plant feedstocks production are taken into account. In both cases, plastic processing, packaging production and transport, as well as final disposal are included. Inputs from the packaged food (production, transport, and impacts associated with food waste at end of-life), use phase and some shorter transport stages are less commonly assessed by LCA practitioners.

\section{Methodology}

\subsection{Systematic literature review}

A systematic literature review was conducted based on the guidelines set by the Centre for Environmental Evidence (CEE, 2013). The process is broadly split into addressing the need for evidence, review scoping and conducting the review (including designing the search strategy, recording the search process, screening, critical appraisal, data extraction and evidence synthesis) (CEE, 2013). The following research question was formulated: How do life-cycle assessments of biodegradable bioplastic and conventional plastics food packaging vary in their environmental impacts and how is food waste considered within the system boundaries? The Web of Science Core Collection was chosen as the citation index service, as it provides access to multiple databases that reference cross-disciplinary research and is regarded as a standard in academia. Following refining of the terms informed by the pilot study (Table S1), the search string was set as:

LCA OR 'life cycle assessment' OR 'life cycle analysis' OR 'environmental impact' OR 'eco-profile' AND bioplastic OR 'biodegradable' OR biopolymer OR 'polylactic acid' OR PLA OR starch OR TPS OR 'thermoplastic starch' AND packaging OR 'multilayer film' OR tray.

All references were recorded and processed by the citation manager RefWorks ProQuest. Articles retrieved from the search were screened for relevance to the research question using a priori inclusion criteria. The short-listed articles were then further examined for critical appraisal and data extraction. At the end of the screening, 19 LCA studies were kept for in-depth assessment. Inclusion criteria were applied at two levels:
i. A first assessment of articles titles and abstracts to remove equivocal hits (e.g. on biopolymer material development rather than packaging assessment); and for those fitting the relevant criteria;
ii. Assessment of the full text based on the following inclusion criteria:
- Packaging material: biodegradable compostable plastic
- Relevant comparators: conventional plastic packaging, or another bioplastic alternative
- Study design: LCA
- Year of study: 2004-2019

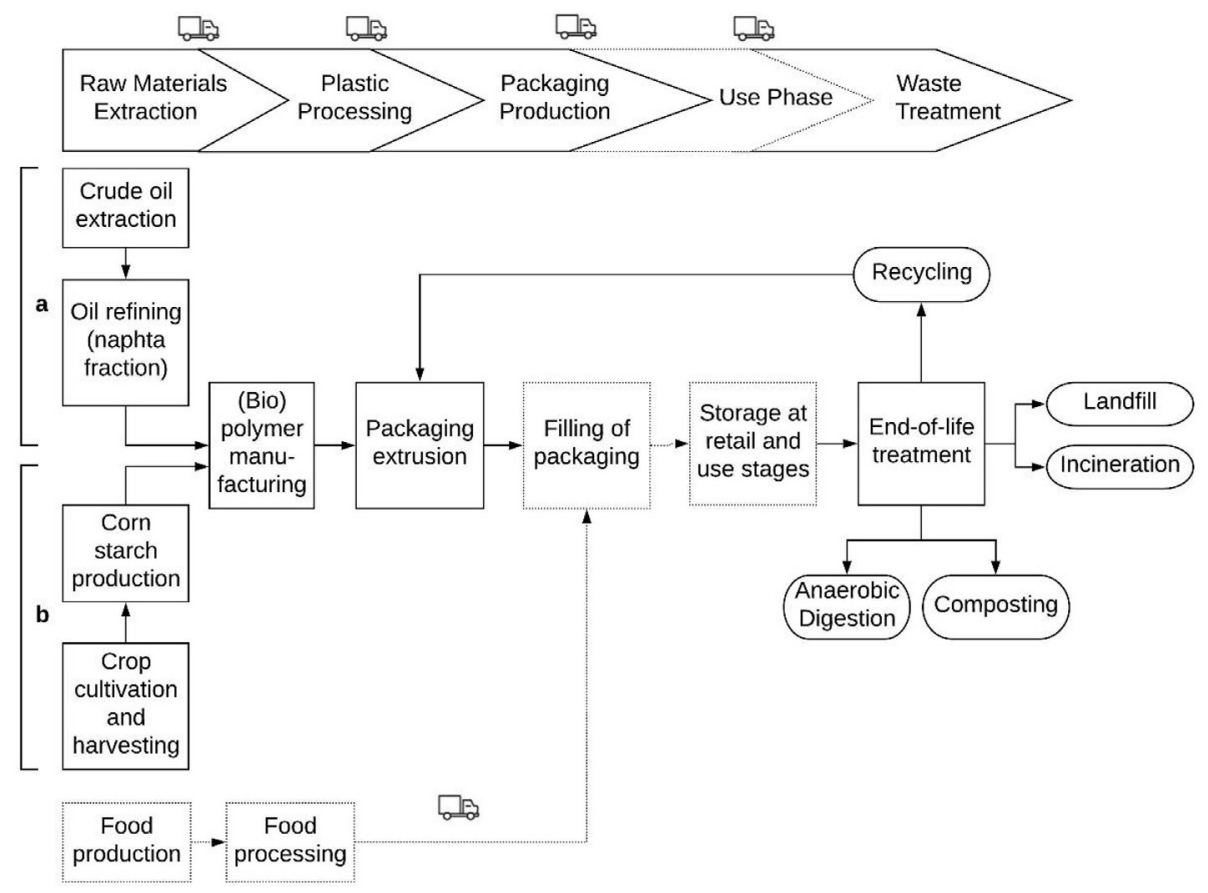

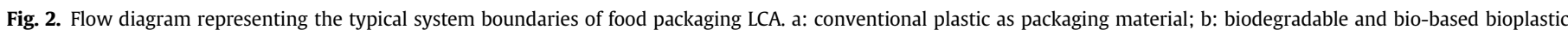

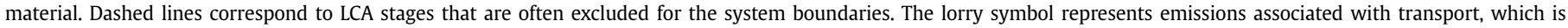
present at all stages. Landfill and incineration are possible end-of-life treatments in both scenarios. 


\subsection{Statistical analysis}

Following the appraisal, relevant data were extracted from each study and recorded on an Excel spreadsheet to form the basis of the literature review. Where possible, numerical data from standard LCA impact categories were extracted and subject to statistical analysis using GraphPad Prism software. Where data were unavailable, or displayed in different metrics, study authors were contacted by email to try to include as many studies as possible in the quantitative assessment.

Studies where values for distinct impact categories were further weighed and normalised (translated into damage-oriented categories, broadly defined as human health, ecosystem quality and resources) were not included, as they are meaningful only within the defined system boundaries of a given study. In some cases, the functional unit was defined in terms of number of packaging units rather than on a per kilogram $(\mathrm{kg})$ of packaging polymer basis. Though meaningful from a methodological point of view, this made it difficult to include some of the studies; where the weight was given, unit conversion was applied in order to yield similar units on a per $\mathrm{kg}$ basis.

The impact categories included in the analysis were chosen based on their frequency of use. It was decided that in order to be included, a given impact category had to be considered by over $30 \%$ of the papers ( $n \geq 6$ ), with two thirds of those containing extractable data $(n \geq 4)$ (see Table 2). This led to the inclusion of global warming potential (GWP), non-renewable energy use (NREU), acidification potential (AP), land use (LU) and water use (W). The median was chosen over the mean, as in it more informative and less skewed by outliers (see Fig. 4).

A similar frequency approach was adopted for the environmental hotspot analysis and end-of-life scenario analysis to maximise statistical robustness of the summary statistics. They focused on GWP and PLA solely because they presented the largest amount of data available for analysis for impact categories and polymer type respectively (see Figs. 5 and 6).

\subsection{Study limitations}

In practice, it is unlikely that all the relevant literature can be identified for several reasons, including data accessibility and research scope (CEE, 2013). Although most articles were accessible through institutional membership, some articles were not retrievable, and some may not be publicly available due to data sensitivity. The study was further limited to papers written in English and published between 2004 and 2019 and focused primarily on EU legislation.

Though essential for comparing LCA findings across multiple studies, converting the functional unit to a per $\mathrm{kg}$ of packaging polymer basis does not fully reflect the real-life performance of any given material. Indeed, even though a given polymer may score poorly in impact categories and would seem less preferable in absolute terms, in reality it may be lighter and less of it would be required for the same application. In addition, due to the inconsistency in impact categories investigated by individual studies, the sensitivity analysis and environmental hotspot analysis were performed for GWP only (see Section 3.2). This does not reflect the authors' view on which impact category is deemed most important. Finally, though this study aims to investigate the role of encompassing food and food waste within the LCA boundaries, the limited number of studies that address food waste has restricted the study to make conclusions on the relationship between polymer type and food waste and instead highlights the research gap of BBPs in the food packaging area.

\section{LCA review analysis}

Based on the eligibility criteria set for the systematic literature review (see Section 3), the following 19 LCA studies were assessed. Table 1 provides the authors, year of publication, the corresponding paper number used in the quantitative analysis and the type of bioplastic material, so that the reader can easily identify which study is being referred to throughout the review. Key paper information, metrics of interest as well as the main findings for each study are presented in Table S2.

Pooling the main conclusions of individual studies together, it becomes apparent that there is no clear advantage for any one type of material in terms of overall environmental performance. Yet, although each study is only truly relevant within its system boundaries and the findings limited by the underlying assumptions, adopting a systematic approach can shed a light on some of the potential trade-offs that may occur between carbon intensity of polymer production, food waste prevention and waste management at the end-of-life (EoL).

\subsection{Food waste-related considerations}

The results demonstrate a lack of LCA studies that consider food waste within their system boundaries, while emphasising the importance of food itself in food packaging LCAs. Indeed, only two studies investigated the effects of food waste prevention (DilkesHoffman et al., 2018; Lorite et al., 2017), as highlighted in Fig. 3. Two further studies (Hottle et al., 2017; Madival et al., 2009) discuss how including GHG emissions related to either food packaging and transportation or landfilling of food waste may impact the conclusions of their respective LCAs. Some studies briefly touch upon the importance of packaging design in shelf-life extension of the packaged food in their introduction, but do not further explore the relationship between food packaging and food waste prevention (Ingrao et al., 2017; Leceta et al., 2013; Venkatesh et al., 2018).

Though eight studies examine food packaging for a particular food application (e.g. yoghurt pots, cheese film packaging, rigid trays for meat or soft fruit), only three include them in their system boundaries, either by looking at impacts at the pre-consumer level (Madival et al., 2009), those associated with extended shelf-life (Lorite et al., 2017) or both (Dilkes-Hoffman et al., 2018). Excluding the food and food waste component from LCA system boundaries can point towards misleading priorities, which may in fact be of lowest importance compared to environmental impacts associated with the production and disposal of food. Indeed, the results from Dilkes-Hoffman et al. (2018) show that food waste dominates packaging LCA, particularly for food produce associated with high environmental production costs, such as meat and dairy.

The more food is spoiled e.g. through non-optimal packaging preservation efficacy, the more food produce and packaging as well as more frequent transportation are required to ensure a certain amount of product is delivered to the customer (Lorite et al., 2017). Thus, ensuring that packaging, regardless of material type, delivers its primary function, which is to preserve the food it contains, should be prioritised (Dilkes-Hoffman et al., 2018).

BBPs offer the opportunity to divert food waste from landfill, thus reducing GHG emissions associated with biodegradable waste in anaerobic conditions (Hottle et al., 2017). This benefit would considerably reduce the environmental impact of bio-waste (Rossi et al., 2015) and that of packaging (Hottle et al., 2017). Assumptions around the rate of anaerobic degradation of biodegradable packaging, particularly of PLA, can strongly influence the results for GWP impacts (Hermann et al., 2010; Hottle et al., 2017; Rossi et al., 2015). When PLA is considered as an inert material, similarly to conventional plastics, landfill often emerges as a suitable EoL, as 
Table 1

Partial reference guide of the assessed literature. Only the first author of the study is shown. PLA: Polylactic Acid; PE: Polyethylene; TPS: Thermoplastic Starch; PBAT: Polybutylene Adipate Terephthalate; PHA: Polyhydroxyalkanoate.

\begin{tabular}{|c|c|c|c|}
\hline Paper \# & Authors & Year & Packaging \\
\hline 1 & Bohlmann & 2004 & PLA yoghurt pots \\
\hline 2 & Vidal et al. & 2007 & PLA-starch film \\
\hline 3 & Krüger et al. & 2009 & PLA clamshells \\
\hline 4 & Madival et al. & 2009 & PLA clamshells \\
\hline 5 & Hermann et al. & 2010 & PLA \& bio-PE snack film \\
\hline 6 & Piemonte & 2011 & PLA clamshells \\
\hline 7 & Deng et al. & 2013 & PLA \& wheat gluten-based films \\
\hline 8 & Leceta et al. & 2013 & Chitosan-based film \\
\hline 9 & Leceta et al. & 2014 & Chitosan-, agar- \& soy protein-based films \\
\hline 10 & Benetto et al. & 2015 & PLA-based clamshells \\
\hline 11 & Rossi et al. & 2015 & PLA \& TPS dry polymer \\
\hline 12 & Hermansson et al. & 2016 & PLA-pulp \& bio-PE-pulp trays \\
\hline 13 & Hottle et al. & 2017 & PLA \& TPS polymer \\
\hline 14 & Ingrao et al. & 2017 & Foamy PLA tray \\
\hline 15 & Lorite et al. & 2017 & Nanocomposite PLA tray \\
\hline 16 & Casarejos et al. & 2018 & Cassava starch tray \\
\hline 17 & Choi et al. & 2018 & PLA \& PLA/PBAT films \\
\hline 18 & Dilkes-Hoffman et al. & 2018 & TPS-PHA films \\
\hline 19 & Venkatesh et al. & 2018 & Starch polymer \\
\hline
\end{tabular}

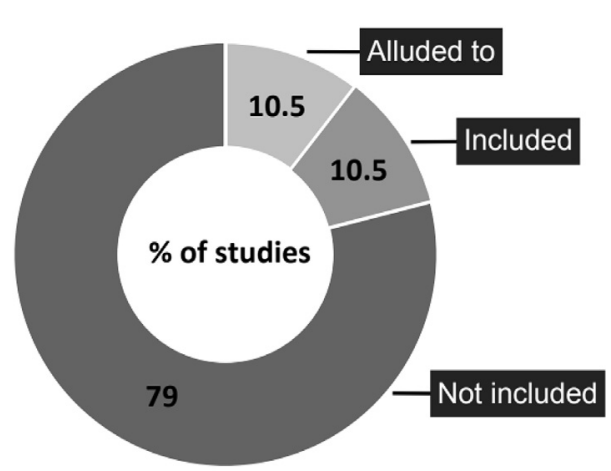

Fig. 3. Percentage of studies considering food waste within their system boundaries. Based on a total number of studies $\mathrm{n}=19$.

carbon is 'locked-in' (Bohlmann, 2004; Choi et al., 2018; Krüger et al., 2009) (Fig. 6).

Arguably, options that consider some sort of material or energy recovery are the best in terms of long-term sustainability (Piemonte, 2011; Rossi et al., 2015). However, as opposed to drop-in bioplastics - bio-based but not bio-degradable plastics chemically identical to conventional plastics -, a suitable recycling scheme for BBPs has still not been developed (Hermansson et al., 2016). This limitation may be detrimental to their application (Hermansson et al., 2016) and questions the merits of biodegradability, since recycling does not call for such properties (Rossi et al., 2015). This highlights the importance of considering bioplastics, particularly BBPs, in the right context. Food contamination, which is often not considered, may hinder the recyclability of food packaging and thus increase both the merits of the biodegradable properties of BBPs and the viability of other EoL scenarios, such as AD or composting (Rossi et al., 2015).

\subsection{Impact categories}

Since LCA international standards ISO 14040 and ISO 14044 provide general guidelines rather than precisely defining the methodology to adopt, studies differ in the nature and range of standard impact categories they consider, ranging from one or two (studies \#1, 6, 17, 18 \& 19) to all (\#10). There is an uneven distribution in the nature of impact categories considered, with a strong bias towards global warming potential (GWP) and non-renewable energy use (NREU), followed by acidification potential (AP), eutrophication potential (EP), respiratory inorganics (RI) and land use (LU), all of which are considered by at least half of the studies $(\mathrm{n} \geq 10$ ) (Table 2).

The results from the quantitative analysis suggest that the environmental impacts of both BBPs and conventional plastics are highly variable and dependent on individual study assumptions. In some cases, significant outliers were observed, and these were subject to further analysis to identify the assumptions underlying such differences.

Both BBPs and conventional plastics show similar GWP impacts, with values ranging from 0.70 to $11.02 \mathrm{~kg} \mathrm{CO} \mathrm{CO}_{2} \mathrm{eq} / \mathrm{kg}$ polymer, excluding the outliers (red circles), which exhibited values above $20.00 \mathrm{~kg} \mathrm{CO} 2 \mathrm{eq} / \mathrm{kg}$ polymer (Fig. 4a). All three outliers stem from Madival et al. (2009) and can be traced back to system boundaries of the study, which include transportation and packaging of the packaged food, in this case strawberries. Similar observations were made for NREU and AP impact categories (Fig. 4b and c). These results highlight that the debate around which polymer, whether bio-biased or conventional, is more sustainable may be trivial next to the environmental impacts of the food produce they aim to preserve. Intriguingly, though this may partly come down to individual LCA methodologies, GWP impacts vary significantly between polylactic acid (PLA) and PLA blends (Fig. 4a). Choi, Yoo \& Park (2018) and Benetto et al. (2015) both found that PLA blended with other biodegradable materials may not necessarily offer environmental advantages compared to conventional plastics, as opposed to pure PLA.

Fewer studies were available for assessment of AP, LU and water use (W) impact categories (Table 2). Nevertheless, even on a relatively small sample size, values for BBPs were generally more spread out than for conventional polymers (Fig. 4c, d \& e), but this is partly due to smaller scales used in these graphs. Though of limited statistical power due to variable sample size, there is a trend towards higher impact values for BBPs in comparison with conventional plastics in those categories. This is to be expected, as the BBPs assessed in this report are all bio-based, which means they require agricultural inputs as part of their production stage. The use of fertilisers and water consumption can be substantial for crops in intensive farming conditions (Casarejos et al., 2018). This is often the case of corn production, which PLA and thermoplastic starch 

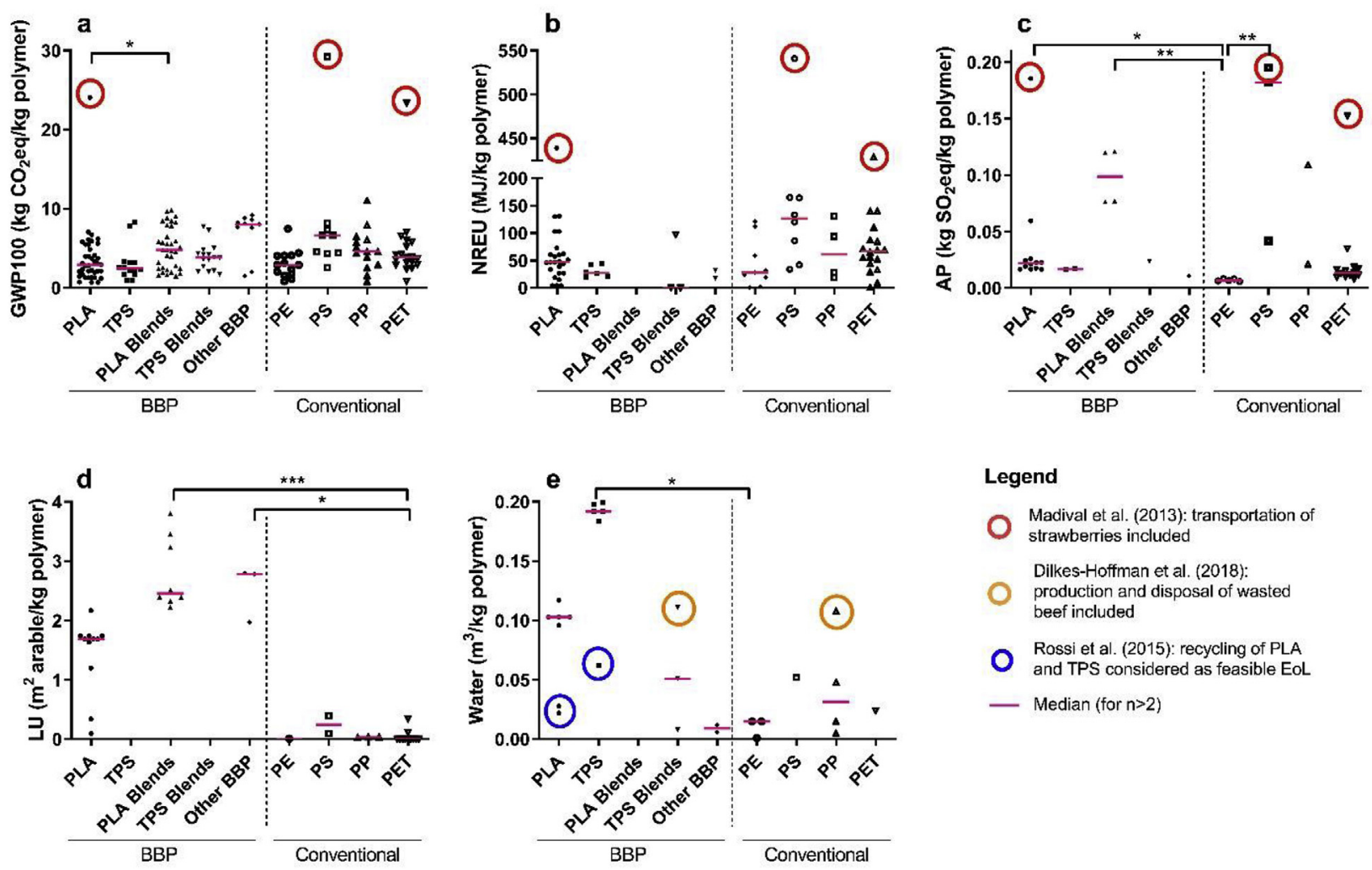

\section{Legend \\ Madival et al. (2013): transportation of strawberries included \\ Dilkes-Hoffman et al. (2018): \\ production and disposal of wastec beef included \\ Rossi et al. (2015): recycling of PLA and TPS considered as feasible EoL}

- Median (for $n>2$ )

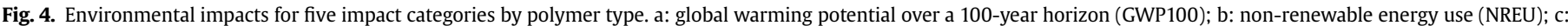

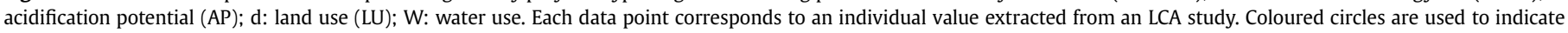

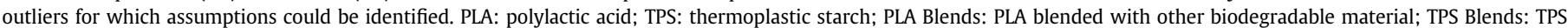

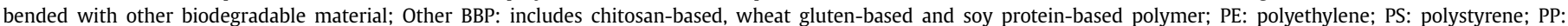

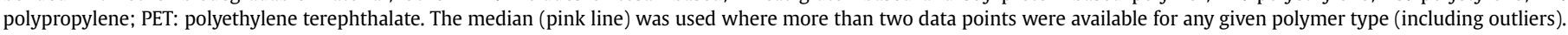

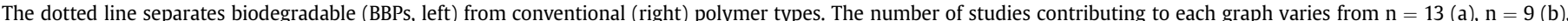

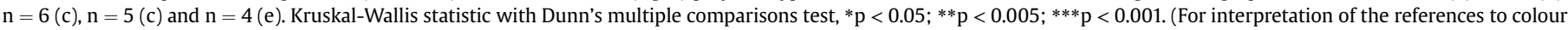
in this figure legend, the reader is referred to the Web version of this article.)

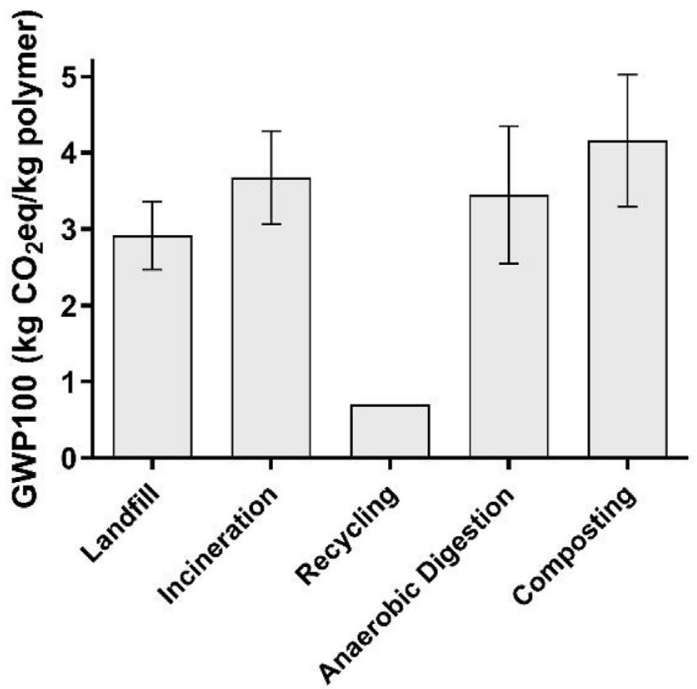

End-of-life options

Fig. 5. Sensitivity analysis for global warming potential based on end-of-life scenario for PLA packaging. Data expressed as mean \pm SEM. The number of studies contributing to each column varies from $\mathrm{n}=8$ (Landfill), $\mathrm{n}=7$ (Incineration), $\mathrm{n}=1$ (Recycling), $\mathrm{n}=2(\mathrm{AD})$ and $\mathrm{n}=4$ (Composting)

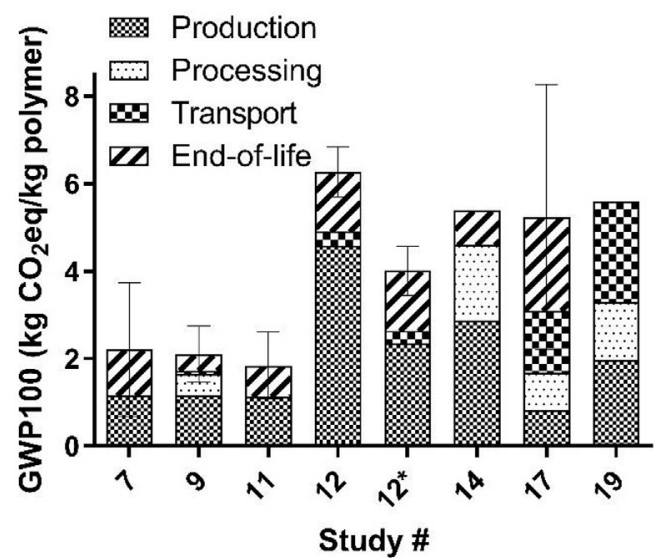

Fig. 6. Contribution of life-cycle stages to overall global warming potential for PLA packaging. For end-of-life, data expressed as mean \pm maximum range based on different disposal methods. *wind credits considered - renewable energy bought in quantities equivalent to the electricity used (Hermansson et al., 2016).

(TPS) are commonly derived from. While there is an environmental burden associated with fossil fuel extraction for the production of conventional plastics, this is usually translated into other categories, such as fossil resources depletion (not included) and NREU, as seen by the often-higher impacts in this category (Fig. 4b). 
Table 2

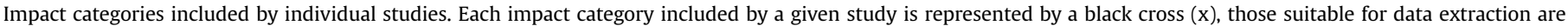

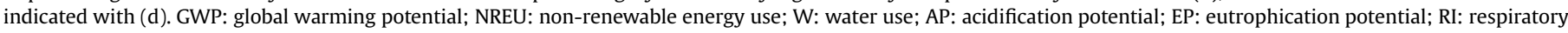

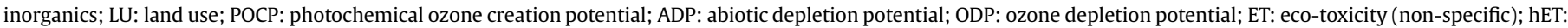
human eco-toxicity; tET: terrestrial eco-toxicity; aET: aquatic eco-toxicity; IR: ionisation radiation; M: mineral extraction; CAR: carcinogens; nCAR: non-carcinogens.

\begin{tabular}{|c|c|c|c|c|c|c|c|c|c|c|c|c|c|c|c|c|c|c|c|c|}
\hline \multirow[t]{2}{*}{ Paper } & \multirow[t]{2}{*}{ Author } & \multirow[t]{2}{*}{ Year } & \multicolumn{18}{|c|}{ Impact Categories Assessed by Individual Studies } \\
\hline & & & GWP & NREU & $\mathrm{AP}$ & $\mathrm{EP}$ & LU & RI & CAR & ODP & nCAR & W & POCP & tET & $\mathrm{aET}$ & IR & M & ADP & hET & ET \\
\hline 1 & Bohlmann & 2004 & $\mathrm{~d}$ & $\mathrm{~d}$ & & & & & & & & & & & & & & & & \\
\hline 2 & Vidal et al. & 2007 & $\mathrm{~d}$ & $\mathrm{~d}$ & d & $\mathrm{d}$ & & & & & & & & & & & & & & \\
\hline 3 & Krüger et al. & 2009 & $\mathrm{~d}$ & $\mathrm{~d}$ & d & $\mathrm{x}$ & $\mathrm{d}$ & $\mathrm{x}$ & $\mathrm{x}$ & & & & d & & & & & & & \\
\hline 4 & Madival et al. & 2009 & $\mathrm{~d}$ & $\mathrm{~d}$ & d & & d & $\mathrm{d}$ & $\mathrm{x}$ & d & $\mathrm{x}$ & & & & d & $\mathrm{d}$ & & & & \\
\hline 5 & Hermann et al. & 2010 & $\mathrm{~d}$ & $x$ & $\mathrm{x}$ & $\mathrm{x}$ & d & & & & & $\mathrm{x}$ & $\mathrm{x}$ & & & & & $\mathrm{x}$ & & \\
\hline 6 & Piemonte & 2011 & $\mathrm{x}$ & $x$ & & & & & & & & & & & & & & & & \\
\hline 7 & Deng et al. & 2013 & $\mathrm{~d}$ & $\mathrm{~d}$ & d & $\mathrm{x}$ & d & $\mathrm{x}$ & $\mathrm{x}$ & d & $\mathrm{x}$ & d & $\mathrm{x}$ & d & d & $\mathrm{d}$ & & & d & \\
\hline 8 & Leceta et al. & 2013 & $\mathrm{x}$ & $\mathrm{x}$ & $\mathrm{x}$ & $\mathrm{x}$ & $\mathrm{x}$ & $\mathrm{x}$ & $\mathrm{x}$ & $\mathrm{x}$ & $\mathrm{x}$ & & & & & & $\mathrm{x}$ & & & $\mathrm{x}$ \\
\hline 9 & Leceta et al. & 2014 & $\mathrm{x}$ & $\mathrm{x}$ & $\mathrm{x}$ & $\mathrm{x}$ & $\mathrm{x}$ & $\mathrm{x}$ & $\mathrm{x}$ & $\mathrm{x}$ & $\mathrm{x}$ & & & & & & $\mathrm{x}$ & & & $\mathrm{x}$ \\
\hline 10 & Benetto et al. & 2015 & $\mathrm{x}$ & $\mathrm{x}$ & $\mathrm{x}$ & $\mathrm{x}$ & $\mathrm{x}$ & $\mathrm{x}$ & $\mathrm{x}$ & $\mathrm{x}$ & $\mathrm{x}$ & $\mathrm{x}$ & $\mathrm{x}$ & $\mathrm{x}$ & $\mathrm{x}$ & $\mathrm{x}$ & $\mathrm{x}$ & $\mathrm{x}$ & $\mathrm{x}$ & \\
\hline 11 & Rossi et al. & 2015 & $\mathrm{~d}$ & $\mathrm{~d}$ & $\mathrm{x}$ & $\mathrm{x}$ & $\mathrm{x}$ & $\mathrm{x}$ & $\mathrm{x}$ & $\mathrm{x}$ & $\mathrm{x}$ & $\mathrm{d}$ & & $\mathrm{x}$ & $\mathrm{x}$ & $\mathrm{x}$ & $\mathrm{x}$ & & $\mathrm{x}$ & \\
\hline 12 & Hermansson et al. & 2016 & $\mathrm{~d}$ & & d & $\mathrm{x}$ & & & & & & & d & & & & & d & & \\
\hline 13 & Hottle et al. & 2017 & $\mathrm{~d}$ & $\mathrm{~d}$ & d & $\mathrm{x}$ & & $\mathrm{d}$ & $\mathrm{d}$ & $\mathrm{d}$ & $\mathrm{x}$ & & $\mathrm{x}$ & & & & & & & \\
\hline 14 & Ingrao et al. & 2017 & $\mathrm{~d}$ & $\mathrm{~d}$ & & & $\mathrm{~d}$ & $\mathrm{~d}$ & & & & & & d & & & & & & \\
\hline 15 & Lorite et al. & 2017 & $\mathrm{x}$ & $\mathrm{x}$ & $\mathrm{x}$ & $\mathrm{x}$ & $\mathrm{x}$ & $\mathrm{x}$ & $\mathrm{x}$ & $\mathrm{x}$ & $\mathrm{x}$ & & & $\mathrm{x}$ & $\mathrm{x}$ & $\mathrm{x}$ & $\mathrm{x}$ & & & \\
\hline 16 & Casarejos et al. & 2018 & $\mathrm{~d}$ & $\mathrm{~d}$ & & & & & & & & $\mathrm{~d}$ & & & & & & & & \\
\hline 17 & Choi et al. & 2018 & $\mathrm{~d}$ & & & & & & & & & & & & & & & & & \\
\hline 18 & Dilkes-Hoffman et al. & 2018 & $\mathrm{~d}$ & & & & & & & & & $\mathrm{~d}$ & & & & & & & & \\
\hline 19 & Venkatesh et al. & 2018 & $\mathrm{x}$ & & & & & & & & & & & & & & & & & \\
\hline Total & & & 19 & 15 & 12 & 11 & 10 & 10 & 9 & 8 & 8 & 6 & 6 & 5 & 5 & 5 & 5 & 3 & 3 & 2 \\
\hline Sub (d) & & & 13 & 9 & 6 & 1 & 5 & 3 & 1 & 3 & 0 & 4 & 2 & 2 & 2 & 2 & 0 & 1 & 1 & 0 \\
\hline
\end{tabular}

The lower values associated with W impact of PLA and TPS (Fig. 4e) were attributed to EoL assumptions by Rossi et al. (2015), where recycling of these biopolymers was considered both economically and logistically viable. In this instance, recycling displayed relatively lower water consumption when compared to other EoL scenarios, given that recycling can reduce the amount of corn that needs to be grown (Rossi et al., 2015). When accounting for production and disposal of the food wasted at the postconsumer level, the results from Dilkes-Hoffman et al. (2018) reemphasise that the highest environmental impact stems from the food packaged rather than the food packaging.

\subsection{End-of-life scenarios}

The EoL scenarios considered by each were investigated. Most studies consider landfill, incineration and industrial composting (14, 13 \& 14 studies respectively), while less than a third (i.e. six studies) consider anaerobic digestion. Though mechanical recycling is included by ten studies, only four of them consider recycling of biodegradable bioplastics (\#6, 11, 12 \& 19). All other studies consider such recycling non-viable based on the current waste management infrastructure and the bioplastic market share and instead focus on well-established recycling lines for conventional plastics, such as PET, PP and PE. Composting is more readily considered over AD as a relevant EoL for BBPs. It is worth questioning whether such preference truly reflects the current infrastructure and policy background, or whether it is merely speculative (see Section 5).

A sensitivity analysis approach was adopted in order to investigate the extent to which EoL scenarios influence the output of LCA analysis for GWP (Fig. 5). The polymer assessed was PLA, as this allowed for the biggest sample size. Although no significance was observed, recycling may offer attractive environmental benefits, as already hinted at previously. This observation is, however, somewhat limited by the fact that they were only two data points available for the recycling category, both from the same study (Rossi et al., 2015). Nevertheless, five other studies support such observation (\#3, 4, 11, 12 \& 13). The results further suggest that $A D$ and composting, which are often perceived as 'greener' EoL options, may not necessarily perform better than landfill or incineration. Indeed, considering that PLA biodegradation in landfill is still contested and EU regulations around methane capture are tightening, landfilling may be considered as a carbon sink (Bohlmann, 2004).

\subsection{Environmental hotspots and trade-offs}

One of the purposes of carrying an LCA is to identify environmental 'hotspots' along the life-cycle of the product examined. The contribution of individual life-cycle stages to GWP for PLA was investigated. Eight papers covering at least production and EoL separately were identified (Fig. 6). In six cases, corn production and PLA granule manufacturing are the major contributors to environmental impacts. This highlights the need for alternative feedstocks, as alluded to by Ingrao et al. (2017). The variability in the data comes down to the underlying assumptions feeding into individual LCA methodologies, and include crop cultivation methods, optimisation of the processing stage, or assumptions about PLA biodegradation in landfill. The EoL stage also displayed significant impacts to the overall score. Depending on the specific EoL scenario, this impact could exhibit even higher GWP values, particularly for Rossi et al. (2015, \#11), Choi et al. (2018, \#17) and Deng et al. (2013, \#7), where the upper range represents about twice the mean value. Where included, results are more variable for transportation, which could be due to geographical differences between individual studies. Nevertheless, they can be significant (cf. \#17 \& 19).

Most studies converge on the detrimental impact of BBP production and processing and the importance of reducing the environmental costs associated with crop cultivation, granule production and film processing, pointing out onto the need for alternative feedstocks. For example, Leceta et al. (2013, 2014) studied biodegradable plastic films made from chitosan, agar and soy protein, all agricultural by-products or waste products, while Deng et al. (2013) and Casarejos et al. (2018) assessed wheat glutenbased and cassava starch-based food packaging respectively. 
Generally, BBPs may provide environmental advantages related to climate change and resources damage categories e.g. for NREU and GWP but being an agricultural product - as opposed to a petrochemical one in the case of conventional plastics - they are compounded by their inherent impacts on ecosystem health. This observation leads to the following points; firstly, the diverse nature of impacts calls for a range of impact categories to be assessed, beyond GWP and NREU. It must be noted, however, that some studies put less emphasis on ecosystem-related impacts when weighing and normalising the data into a single output value (Piemonte, 2011; Lorite et al., 2017; Ingrao et al., 2017). Secondly, there is a need for more accurate models that take into account the dynamics of GHG releases and over longer time horizons (Rossi et al., 2015; Dikes-Hoffman et al., 2018).

Several studies emphasise that environmental LCAs alone cannot - and should not - provide a binary answer for decisionmaking in the 'real world' (Rossi et al., 2015; Venkatesh et al., 2018). Indeed, cost-effectiveness comes into play (Benetto et al., 2015); economics, functionality and social acceptance are as, if not more so important (Venkatesh et al., 2018). Thus, in order to define the final preference for any one polymer family one must apply value judgements (Krüger et al., 2009).

\section{Discussion}

\subsection{The need for LCA boundaries encompassing all aspects of packaging}

The results have demonstrated that packaging LCAs are often undertaken in isolation of the food produce they are designed to protect. This finding aligns with the literature (Molina-Besch et al., 2019; Verghese et al., 2014). However, LCA boundaries need to be broadened to encompass all environmental impacts, including those associated with food production and food waste (Verghese et al., 2014). Since food waste dominates food packaging LCA (Dilkes-Hoffman et al., 2018) any measure to reduce the former, even to a small extent, can reduce the overall environmental profile of the food produce-food packaging system.

A correlation of food waste with a certain type of packaging can only be established if exactly the same product is packaged in two different packaging materials, or is available packaged as well as unpackaged, and different loss rates can be observed (Pauer et al., 2019). Of the 19 studies reviewed, those that considered packaging with a specific application in mind all differed in the nature of the packaged food. Moreover, when doing a comparative analysis of conventional plastics and BBPs, only if the alternative biodegradable packaging materials are associated with equal amount of food waste and food losses throughout the supply chain may the food and food waste aspects be excluded from the LCA (Flanigan et al., 2013). If they are not included, it is important to justify such decision (Flanigan et al., 2013).

Considering not only food packaging but also the packaged food in the system can enhance sustainability throughout the food supply chain (Verghese et al., 2014). This is particularly true when the environmental impact of the packaging is expected to be low compared to the packaged food itself (Dilkes-Hoffman et al., 2018; Flanigan et al., 2013). From a life-cycle perspective, GHG emissions associated with food waste are often larger than those of plastic packaging (Zero Waste Scotland, 2016). This includes high climate impact foods per $\mathrm{kg}$ (e.g. animal products) or high climate impact foods for total waste (e.g. fruit and vegetables, which do not have a high impact per $\mathrm{kg}$ but the accumulation of food waste leads to high impact) (Verghese et al., 2014). In such cases, focusing on food waste reduction can be an effective strategy to limit GWP impacts of food-packaging systems (Dilkes-Hoffman et al., 2018).
Most studies converge on the importance of packaging functionality when assessing the environmental profiles of alternative polymers and designs. Interestingly, this was rarely translated in how the functional unit was defined. Only three studies investigated packaging in the context of a certain amount of fresh food produce to be delivered at the retail or consumer phase (Bohlmann, 2004; Dilkes-Hoffmann et al., 2018; Lorite et al., 2017). Most studies focused on a per $\mathrm{m}^{2}$ of polymer for film packaging or per $\mathrm{kg}$ basis for rigid packaging, which may however confer some advantages for drawing broader conclusions and enabling comparisons between studies (Bohlmann et al., 2004; Yates and Barlow, 2013).

Aiming to reduce the amount of packaging material for a given application when implementing changes in packaging design may also lead to unintended increases in food wastage (Williams and Wikström, 2011). The selection criteria for any one packaging material and design should thus consider both effectiveness - the ability to maintain quality and extend shelf-life - and efficiency the minimisation of environmental impact and costs generated by packaging production and disposal (Ingrao et al., 2017; Licciardello, 2017). A circular packaging is in the best-case reusable or, when produced from renewable or recycled materials and after its use, it is either recycled or composted (Ellen MacArthur Foundation, 2019).

\subsection{Limitations \& opportunities for bioplastics}

Packaging design and polymer preference should focus on functionality. Yet, in many cases bioplastics fail to deliver the mechanical and physio-chemical properties necessary for food preservation and further shelf-life expansion (Lorite et al., 2017). The inherent properties of bio-sourced polymers that confer them obvious advantages in terms of biodegradability also limit their applications (Lorite et al., 2017). These include poor barrier properties, brittleness and water permeability (Averous, 2004). Thus, if bioplastics are to become a larger part of the food packaging market, further research into enhancing their functional performance is needed.

When assessing and comparing BBPs to their petrochemical counterparts, it is worth clearly distinguishing between two key characteristics of BBPs:

- bio-based, relating to the nature of feedstock origin, in this case of renewable sources;

- biodegradable, relating to how packaging waste can be disposed of at the end-of-life.

This distinction is important, as it shows that the benefits of BBPs may not necessarily lie in their feedstock origin but rather in the fact that they provide opportunities at the EoL. Biodegradability and the benefits it may offer are explored in-depth in the following section. Further research is needed into the extent of biodegradation of the different biopolymers (Yates and Barlow, 2013). On the one hand, replacing conventional plastics with bio-based plastics made from renewable feedstocks is frequently proposed as a way to mitigate GHG emissions and energy use associated with plastics production (Posen et al., 2017). On the other hand, land use change associated with agricultural feedstocks for bioplastic production can cause significant GHG emissions, especially if rainforests, grasslands or peatlands are being displaced (Piemonte and Gironi, 2011).

In the long run, if governments are to reach net zero carbon economies, all coal, gas and oil-related industry will have to cease, and so will the petrochemical plastic industry. Thus, alternatives to conventional plastics have a role to play. However, we need to make sure these do not generate new, unintended GHG emissions, 
particularly through agricultural inputs and land-use changes. Innovation opportunities and alternatives feedstocks need to be considered.

The optimisation potential of BBPs and other bioplastics is significant (European Bioplastics, 2017). The biopolymer and oleochemical industry - which supplies the chemicals for the modification and compounding in biopolymer production - is still young and thus has a lower optimisation degree (Vidal et al., 2007). This potential should be taken into consideration when assessing material preference; otherwise LCA becomes a tool which tends to hinder innovation by favouring already optimised material streams (European Bioplastics, 2017).

Working towards higher sustainability goals, a few studies have investigated alternative feedstocks (Casarejos et al., 2018; Deng et al., 2013; Leceta et al., 2013, 2014). Advanced feedstocks offer particularly attractive advantages due to their high agro-ecological adaptation (Casarejos et al., 2018), as well as the possibility to expand onto social and economic sectors. For example, cassava, a tuber native to South America, can be grown on marginal land unsuitable for food production, with little or no irrigation and requires low infrastructure, thus supporting small-scale producers with limited financial capacity to operate locally in the Brazilian market (Casarejos et al., 2018). Producing bio-based bioplastics from advanced feedstocks (e.g. switchgrass or cassava) and with renewable energy can further reduce emissions to a neutral carbon (0 kg CO 2 eq/year) balance (Posen et al., 2017).

Pushing the boundaries even further and seeking a truly circular system, there has been a growing interest in bioplastic production from waste or by-products, such as soy protein, chitosan (from the outer skeleton of shellfish) and seaweed (Casarejos et al., 2018; Leceta et al., 2013, 2014). The entrepreneurial sphere associated with bioplastic-related start-ups has been flourishing and expanding, including projects developing bioplastics made from marine kelp, food waste or lobster shells (Marine Biopolymers, 2013; Genecis, 2018; The Shellworks, 2019).

Perhaps innovation opportunities with an arguably bigger impact lie in the development of more effective and efficient bioplastics, particularly in multilayer film packaging applications. The introduction of additives e.g. nanoclays and surfactants, was shown to enhance the performance of PLA similar to that of PET, reduce food loss through extending the shelf-life of food produce and prevent microbial growth (Lorite et al., 2017). Moreover, the combination of multiple layers of various materials with distinct properties is particularly promising for BBPs. For example, TPS exhibits high water permeability but low oxygen permeability in comparison with most conventional polymers (Averous, 2004), particularly advantageous for fresh food packaging, which require packaging to let moisture out (Lorite et al., 2017). However, it requires further optimisation (Guo and Murphy, 2012). Indeed, plasma treatment, a step necessary to improve the compatibility of different biopolymers in multilayer films, contributes significantly to the environmental impact over the life-cycle of film packaging (Benetto et al., 2015).

Finally, though this applies to all plastic packaging, not just BBPs, opportunities exist for designing packaging aimed to meet the needs and demands of the consumers (Lorite et al., 2017). LCAs looking at packaging 'extras', e.g. additives, modified atmosphere packaging, etc. and packaging formats e.g. single-serving versus bulk, should be conducted (Verghese et al., 2014).

\subsection{Biodegradability in a circular economy framework}

In a circular context, biodegradability as a packaging property is often positively perceived (Yates and Barlow, 2013) and is sometimes defined as a 'green metric' in packaging design (Tabone et al.,
2010). Though BBPs are often put forward as a solution to the environmental burden of plastic pollution, their release into the environment can still be harmful to the ecosystem (Narancic et al., 2018). The benefits of biodegradability need to be carefully considered and understood in a particular waste management context.

Further research is needed to understand the extent to which different BBPs biodegrade in a range of managed and unmanaged environments (Narancic et al., 2018; Yates and Barlow, 2013). In a highly-disseminated study, researchers at the University of Plymouth showed that in many cases, plastic carrier bags labelled as 'biodegradable' did not display significantly advantageous deterioration rates in marine or soil environments, even after three years, when compared to conventional plastics (Napper and Thompson, 2019). In another study, biodegradation rates of PLA and PLA blends were shown not to significantly differ from those of non-degradable plastics in both marine and freshwater aqueous environments in two months of testing (Narancic et al., 2018). Results from biodegradability of bioplastic food packaging in simulated home composting systems suggest that it is important to distinguish BBPs that can biodegrade under ambient conditions found in home composting from those that only do so under more elevated temperatures of industrial composting facilities (Song et al., 2009). These distinctions need to be communicated to the wider public through accurate labelling schemes (Song et al., 2009), which would boost public trust while limiting opportunities for 'green-washing' (European Bioplastics, 2017).

The benefits of biodegradability are often debated in the context of plastic littering. None of the studies considered in the analysis considered littering in their LCA, as was previously recorded in the literature (Spierling et al., 2018). However, this EoL scenario ought not to be excluded, with estimates showing that up to $32 \%$ plastic packaging currently ends up leaking into the environment (World Economic Forum, Ellen MacArthur Foundation \& McKinsey and Company, 2016). It is important to bear in mind, however, that littering is a behavioural rather than environmental problem, which needs to be tackled by education, not technology (Andrady and Neal, 2009). It can be argued that designing and testing BBPs for biodegradability in unmanaged disposal scenarios is misleading the public's perception of the value of new alternative packaging materials, as BBPs are not designed to be littered (European Bioplastics, 2017).

Beyond the most apparent advantages of biodegradability for EoL management, other aspects can also tip the balance in favour of BBPs. For example, biodegradable food packaging can contribute to an increase in composting and AD rates of food waste (Razza and Degli Innocenti, 2012). The benefits of creating an easily compostable waste stream to avoid $\mathrm{CH}_{4}$ generation from food waste may outweigh the emissions associated with composting PLA (Hottle et al., 2017). In addition, other factors difficult to capture in LCA include compost as a vital source of soil carbon. Though there is no consensus in the literature on the benefit of a nutrientfree carbon-based compost (Rossi et al., 2015; Vidal et al., 2007), added carbon content alone can help in moisture retention, counterbalance soil erosion and act as pest and disease control (Yates and Barlow, 2013). Climate change and intensified agricultural practices are threatening the fertility of soils worldwide; composting and AD sludge may thus provide a useful source of soil organic carbon, contributing to restoration of depleted soils, such as in the Mediterranean basin (Vidal et al., 2007).

Proper waste management is a key element in ensuring efficiency and sustainable growth. Perhaps unsurprisingly, mechanical recycling is often put forward as the preferred option over composting or $\mathrm{AD}$, even for bioplastics, where drop-ins perform better than BBPs, since they can be recycled alongside conventional 
plastics (Hottle et al., 2017; Piemonte, 2011; Rossi et al., 2015). However, a recycling 'cascade cycle' approach can be difficult to achieve for short-lived, often food-contaminated packaging products, which currently account for $70 \%$ of bioplastic market share and are expected to rise to $84 \%$ by 2025 (Spierling et al., 2018).

The revised European Waste Framework Directive supports the deviations from the hierarchy in cases where other priorities would be more environmentally friendly (Rossi et al., 2015). Some of the literature reviewed has shown that incineration with sufficient energy recovery, which does not require biodegradation, could have lower environmental impacts than AD and composting (Choi et al., 2018; Rossi et al., 2015), thus making the benefits of biodegradability questionable (Yates and Barlow, 2013).

\subsection{Reframing the debate}

There is a clear consensus that simply removing plastic packaging from the food supply chain does not necessarily contribute to overall environmental sustainability (Iacovidou and Gerassimidou, 2018). There are many cases where plastic packaging can reduce food wastage (WRAP, 2018). Dilkes-Hoffman et al. (2018), who included the packaged food product into their assessment, concluded that a given packaging design is desirable if it results in less food waste. Such conclusions are based on the argument that the production of one more unit of food product causes greater environmental damage than the production and waste management of one more unit of packaging. This holds particularly true for products such as meat and dairy, where the environmental impact from the agricultural inputs of a single unit can be substantial (Dilkes-Hoffman et al., 2018).

However, growing awareness of the problematic aspects of packaging waste and pollution, especially for plastics, alongside persistently high levels of food waste have raised concerns about the legitimacy of those claimed benefits (Schweitzer et al., 2018). Indeed, with $70 \mathrm{~kg}$ of per capita household food waste and $30 \mathrm{~kg}$ of per capita plastic packaging waste per year, European waste levels are among the highest globally (31 Mt and 15 Mt per year respectively) (Eurostat, 2019; Schweitzer et al., 2018). These statistics on food and plastic packaging waste suggest that the considerable levels of plastic packaging have had no or little effect on food waste reduction (Schweitzer et al., 2018). The practical and economic limitations of plastic polymer recycling have already been recognised since the 1990's (Stein, 1992). While investment in advanced recycling technologies is needed to address the current volume of plastic waste, recycling itself does not put enough emphasis on a truly circular system, as the same business model of designing cheap, single-use disposable packaging is maintained (Lemille, 2019).

With the integrity of the ecosystems our food systems ultimately rely upon under threat, it is worth thinking about ways to redesign our food systems so that they are better suited to the new challenges our societies have already begun to face. In addition, a great amount of food wastage is generated at the consumer level or set by aesthetic standards, so perhaps the contribution of bioplastics may not be as relevant to food sustainability and may even limit the implementation of more systemic changes across the food supply chain (Schweitzer et al., 2018). Moreover, the emergence of an 'on-the-go' culture as well as demographic changes underpinned by the rise of single-person households (Eurostat, 2018) are often responsible for higher levels of waste (Verghese et al., 2014).

Focusing on 'greener' alternatives to petrochemical plastic does not address the growing awareness of the impact of packaging waste and the urgent need for an absolute reduction in the use of all resources (Schweitzer et al., 2018). The convenience offered by any single-use plastics must not override the priority of eliminating unnecessary and problematic plastic packaging through redesign and innovation (World Economic Forum \& Ellen MacArthur Foundation, 2017).

Based on the findings from the systematic literature review, there is an incentive to reduce transport distances. High food mileage is associated with increased GHG emissions as well as the need for packaging for conservation and transportation. Therefore, to reduce the amount of plastic that is needed, while avoiding burden shifting onto food waste levels, short food supply chains must be developed where possible (Iacovidou and Gerassimidou, 2018). Such systems involve fewer intermediaries between the farm (production stage) and the household (consumption stage), reducing the need for packaging. With over half of the world population now living in cities (UN, 2018), vertical farming has been gaining momentum, as a production system that is both closer to the consumer (as it can be developed in urban in peri-urban spaces) and operated in a closed-loop system, arguably more efficient (Benke and Tomkins, 2017).

Strikingly, food losses in developed countries are as high as in developing countries, but while in the latter over $40 \%$ occur at postharvest and processing levels, in the former more than $40 \%$ occur at retail and particularly consumer levels (FAO, 2011). Thus, educational campaigns aimed at raising consumers' awareness on their waste-generating habits may be a more effective way to improve the sustainability of the food supply chain than developing green alternatives to plastic packaging. Indeed, solutions at producer and manufacturer level would only be marginal if consumer continue to waste at current levels. Farmers' markets, community-based growers and local basket delivery systems help connect consumers to where their food is produced in ways that can also help reduce food packaging and waste (Iacovidou and Gerassimidou, 2018). With the inevitable environmental impacts of food production and consumption on the Earth's natural resources, systemic changes also involve switching to more seasonal, local and plantbased diets (Willett et al., 2019).

\section{Recommendations \& future studies}

It is important to recognise the advantages but also the limitations of BBPs in order to fully understand where the opportunity for compostable substitution lies. Encouraging BBPs should target plastic packaging where effective recycling measures are failing (Massey et al., 2019). Understanding which plastics can be recycled and for which ones there is an economic incentive to do so are thus important considerations that need to be taken into account when assessing the potential for the BBP market. Compostable substitution should be focused in the area of multi-layer food packaging, due to the challenges that remain for treating and recycling materials made of multiple layers, including plasticisers and adhesives (Massey et al., 2019). In addition, food contamination represents a serious issue undermining the viability of plastic packaging recycling as additional cleaning steps make the process more expensive (Rossi et al., 2015; Massey et al., 2019). Thus, the scope of food packaging products that are most appropriate for substitution are:

- Bag liners for household food waste collections;

- Multi-layer food packaging e.g. crisp bag, pouches;

- Fresh food packaging e.g. fruit and vegetables, bread, cheese, meat film or trays;

- Food on-the go e.g. sandwich wrappers, clamshell trays.

Beyond the theoretical market opportunities for BBPs, estimated to generate an economic benefit of $£ 267 \mathrm{~m}$ by 2025 in the UK (Massey et al., 2019), current and future policies are an important consideration when evaluating the role of BBPs. BBPs can help 
achieve the ambitions set by governments to reduce food waste to landfill, but promotion of BBPs needs to come hand in hand with measures to facilitate the transition to such alternative plastic packaging, including:

- More harmonious collection system (particularly within municipalities);

- Consistent waste management infrastructure (note that it is vital that compostable packaging materials are consistent to ensure confidence in industrial composters and AD operators to allow such materials through their plants);

- Clear labelling and caution with greenwashing.

Composting as a disposal method is currently limited. The majority of the studies analysed in this review assume composting as EoL for BBPs. In 2008, $17 \%$ of EU's municipal waste was composted (EU, 2010). The majority comes from garden waste, which is has less stringent requirements than food and food-contaminated packaging waste require (EU, 2008). Thus, current open-air windrow composting facilities would not be a suitable EoL under the current Animal By-Products Waste Regulation (EU, 2009), which requires a closed system for the treatment of material fits for human consumption in the form of in-vessel composting. Such restrictions lower the competitiveness of composting when compared to other cheap disposal methods such as landfill (Song et al., 2009).

Since AD generates biogas from methane $\left(\mathrm{CH}_{4}\right)$ production, it may represent a more valuable EoL than composting (Narancic et al., 2018). The Committee on Climate Change has identified biogas as a 'low regret option' that could provide a greener alternative to natural gas for heat and electricity generation (Committee on Climate Change, 2013). According the Anaerobic Digestion \& Bioresources Association (ADBA), AD has the potential to reduce global $\mathrm{CO}_{2}$ emissions by over $10 \%$ by 2030 , helping countries to reach the ambitions set in the Paris Agreement (ADBA, 2020). Using available food waste and food loss for AD biogas production has the potential to generate 880 to 1100 TWh of energy (Jain, 2019) enough to meet the electricity demand of up to 135 million people worldwide (The World Bank, 2019). BBPs have high biochemical $\mathrm{CH}_{4}$ potential and display a high $\mathrm{C}: \mathrm{N}$ ratio, indicating that these plastics should positively contribute to $\mathrm{CH}_{4}$ production in $\mathrm{AD}$ of mixed wastes containing food waste (Narancic et al., 2018).

Yet, uncertainties around the suitability of BBPs for AD currently cause AD facilities to show some reluctance to accept bioplastics (European Bioplastics, 2015). First, it can be challenging to distinguish biodegradable from non-biodegradable plastics in AD and composting screening. Nevertheless, recent studies demonstrate that optical sorting systems could easily identify and separate them (Plastics Europe, 2018). Second, most BBPs are certified for specific environments in industrial (aerobic) composting conditions (European Bioplastics, 2015), which differ from an anaerobic environment. Though the majority of BBPs can biodegrade in AD, their degradation time is three to six times longer than the typical retention time in industrial AD plans (Narancic et al., 2018). While research should focus on developing biopolymers fit for industrial settings, the waste infrastructure may also need to adapt to the evolving composition of waste (Narancic et al., 2018).

Following the analysis of the information gathered from the LCA studies and in light of the political and social drive to reduce plastic packaging, the following research gaps where identified:

I. First, there is a clear lack of LCAs that include food waste within their system boundaries. LCA practitioners are encouraged to include food waste in their analysis to better depict the environmental profile of a food/packaging system;
II. Secondly, further research into biopolymers made from waste products and alternative feedstocks might help optimise the sustainability of BBPs;

III. Thirdly, the relationship between shelf-life extension and food waste prevention is still unclear and would benefit from further examination of the trade-offs between plastic packaging reduction and increased food waste;

IV. Lastly, scientific evidence is needed to understand the extent to which different BBPs biodegrade in a range of managed and unmanaged environments.

\section{Conclusions}

The issue of plastic food packaging lies at the heart of sustainable food supply chains. With more extended and complex food supply chains, an increasing amount of food items require packaging to ensure food delivery from farm to fork. Growing concerns over current rates of plastic waste generation have led to the development and promotion of bioplastics as 'greener' alternatives to oil-based, non-biodegradable polymers. This review adopted a systematic approach to address the sustainability of bioplastic food packaging, with a life-cycle perspective. Following a review of 111 papers, 19 were identified for further investigation and data extraction. Quantitative analysis for five impact categories, as well as hotspot analysis and end-of-life scenario analysis for GWP were conducted.

- Results depict an inconclusive picture for bioplastics and highlight the complexity of the issue and the many trade-offs at play.

- The LCAs included in this study do not provide enough evidence to state which polymer is best at reducing food waste, but rather emphasise the importance of including the food itself in food packaging LCAs. The environmental impacts of food produce are often significantly higher than those associated with packaging, regardless of the nature of the plastic material.

- Agricultural inputs for feedstock production of BBPs often negate environmental benefits. Alternative feedstocks and innovations in barrier properties are already being investigated, which should enhance the performance of BBPs.

- There is an inconsistency in LCA impact categories, with GWP remaining the predominant impact category studied.

- Bioplastics allow to divert food waste from landfill to alternative streams, such as composting and anaerobic digestion, but further research needs to assess their biodegradability in various managed and unmanaged environments.

- The relevant waste management infrastructure must be developed if the biodegradability benefits of BBPs are to be fully harnessed.

- There is an opportunity to consider more systemic changes beyond conventional food supply chains, such as short food supply chains or package-free and reusable packaging solutions, which design waste out of the system rather than simply optimise the status quo.

\section{Declaration of competing interest}

The authors declare that they have no known competing financial interests or personal relationships that could have appeared to influence the work reported in this paper.

\section{Acknowledgements}

We thank William McManus for his support at the scoping stage. We would also like to thank the editors and anonymous 
reviewers for their comments and feedback on the manuscript. SK was supported by the Economic and Social Research Council through a London Interdisciplinary Social Sciences Studentship (ES/ P000703/1). ZMH was supported by a Natural Environment Research Council Industrial Innovation Fellowship (NE/R013314/1).

\section{Appendix A. Supplementary data}

Supplementary data to this article can be found online at https://doi.org/10.1016/j.jclepro.2020.122831.

\section{References}

ADBA, 2020. Biomethane: the pathway to 2030. ADBA, London.

Advisory Committee on Packaging, 2008. Packaging in perspective. In: Advisory Committee on Packaging.

Andrady, A.L., Neal, M.A., 2009. Applications and societal benefits of plastics. Phil. Trans. Biol. Sci. 364 (1526), 1977-1984.

Averous, L., 2004. Biodegradable multiphase systems based on plasticized starch: a review. J. Macromol. Sci. Polym. Rev. 44 (3), 231-274.

Benetto, E., Jury, C., Igos, E., Carton, J., Hild, P., Vergne, C., Di Martino, J., 2015. Using atmospheric plasma to design multilayer film from polylactic acid and thermoplastic starch: a screening Life Cycle Assessment. J. Clean. Prod. 87, 953-960.

Benke, K., Tomkins, B., 2017. Future food-production systems: vertical farming and controlled-environment agriculture. Sustain. Sci. Pract. Pol. 13 (1), 13-26.

European Bioplastics, 2017. Environmental Communication Guide for Bioplastics. European Bioplastics, Berlin.

Bohlmann, G.M., 2004. Biodegradable packaging life-cycle assessment. Environ. Prog. 23 (4), 342-346.

Brockhaus, S., Petersen, M., Kersten, W., 2016. A crossroads for bioplastics: exploring product developers' challenges to move beyond petroleum-based plastics. J. Clean. Prod. 127, 84-95.

Buranyi, S., 13 Nov 2018. The plastic backlash: what's behind our sudden rage - and will it make a difference? Guardian. Available from: https://www.theguardian. com/environment/2018/nov/13/the-plastic-backlash-whats-behind-oursudden-rage-and-will-it-make-a-difference. Accessed 30th July 2019.

Casarejos, F., Bastos, C.R., Rufin, C., Frota, M.N., 2018. Rethinking packaging production and consumption vis-a-vis circular economy: a case study of compostable cassava starch-based material. J. Clean. Prod. 201, 1019-1028.

Choi, B., Yoo, S., Park, S., 2018. Carbon footprint of packaging films made from LDPE PLA, and PLA/PBAT blends in South Korea. Sustainability 10 (7), 2369.

Collaboration for Environmental Evidence, 2013. Guidelines for Systematic Review and Evidence Synthesis in Environmental Management. Environmental Evidence, Bangor. Version 4.2.

Committee on Climate Change, 2013. Reducing the UK's Carbon Footprint. Committee on Climate Change, London.

Ocean Conservancy, 2017. Together for Our Ocean - International Coastal Cleanup 2017 Report. Ocean Conservancy, Washington, D.C.

Deng, Y., Achten, W.M.J., Van Acker, K., Duflou, J.R., 2013. Life cycle assessment of wheat gluten powder and derived packaging film. Biofuels Bioprod. BiorefiningBiofpr. 7 (4), 429-458.

Dilkes-Hoffman, L.S., Lane, J.L., Grant, T., Pratt, S., Lant, P.A., Laycock, B., 2018 Environmental impact of biodegradable food packaging when considering food waste. J. Clean. Prod. 180, 325-334.

Ellen MacArthur Foundation, 2019. Cities and Circular Economy for Food. Ellen MacArthur Foundation.

European Bioplastics, 2015. Anaerobic Digestion Fact Sheet. European Bioplastics, Berlin.

European Bioplastics, 2016. What Are Bioplastics? Material Types, Terminology, and Labels: an Introduction. European Bioplastics, Berlin.

European Union, 2008. Directive of the European Parliament and of the Council of 19 November 2008 on Waste and Repealing Certain Directives. European Parliament and Council of the European Union, Strasbourg. Report number: (2008/98/EC).

European Union, 2009. Regulation of the European Parliament and of the Council of 21 October 2009 Laying Down Health Rules as Regards Animal By-Products and Derived Products Not Intended for Human Consumption and Repealing Regulation (EC) No 1774/2002. European Parliament and Council of the European Union, Strasbourg. Report number: (2009/1069/EC).

European Union, 2010. Being Wise with Waste: the EU's Approach to Waste Management. Publications Office of the European Union, Luxembourg.

European Union, 2015. Closing the Loop - an EU Action Plan for the Circular Economy. European Parliament, European Council, European Economic and Social Committee \& Committee of the Regions.

European Union, 2016. Life Cycle Thinking and Assessment for Waste Management. European Commission, Luxembourg.

European Union, 2018. A European Strategy for Plastics in a Circular Economy European Commission, Brussels.

Eurostat, 2018. Rising Proportion of Single Person Households in the EU. Available from: https://ec.europa.eu/eurostat/web/products-eurostat-news/-/DDN20180706-1?inheritRedirect=true. Accessed 18th July 2019.
Eurostat, 2019. Municipal waste statistics. Available from: https://ec.europa.eu/ eurostat/statistics-explained/index.php/Municipal_waste_statistics. Accessed 30th July 2019.

FAO, 2011. Global Food Losses and Food Waste - Extent, Causes and Prevention. FAO, Rome.

FAO, 2019. Food Loss and Food Waste. Available from: http://www.fao.org/foodloss-and-food-waste/en/. Accessed 17th May 2019.

Flanigan, L., Frischknecht, R., Trisha, M., 2013. An Analysis of Life Cycle Assessment in Packaging for Food and Beverage Applications. Life Cycle Initiative UNEP/ SETAC, Paris.

Genecis, 2018. High performance bioplastics. Available from: https://genecis.co/. Accessed July 30th 2019.

Gillick, S., Quested, T., 2018. Household Food Waste: Restated Data for 2007-2015. WRAP, Banbury.

Guo, M., Murphy, R.J., 2012. Is there a generic environmental advantage for starchPVOH biopolymers over petrochemical polymers? J. Polym. Environ. 20 (4), 976-990.

Heller, M.C., Selke, S.E., Keoleian, G.A., 2019. Mapping the influence of food waste in food packaging environmental performance assessments. J. Ind. Ecol. 23 (2), 480-495.

Hermann, B.G., Blok, K., Patel, M.K., 2010. Twisting biomaterials around your little finger: environmental impacts of bio-based wrappings. Int. J. Life Cycle Assess, 15 (4), 346-358.

Hermansson, F., Janssen, M., Gellerstedt, F., 2016. Environmental evaluation of durapulp bio-composite using Lca: comparison of two applications. Journal of Science \& Technology for Forest Products and Processes 5 (2), 68-76.

HM Government, 2018. Our Waste, Our Resources: a Strategy for England. HM Government, London.

Hottle, T.A., Bilec, M.M., Landis, A.E., 2013. Sustainability assessments of bio-based polymers. Polym. Degrad. Stabil. 98 (9), 1898-1907.

Hottle, T.A., Bilec, M.M., Landis, A.E., 2017. Biopolymer production and end of life comparisons using life cycle assessment. Resour. Conserv. Recycl. 122, 295-306.

Iacovidou, E., Gerassimidou, S., 2018. Sustainable packaging and the circular economy: an EU perspective. Reference Module in Food Science.

Ingrao, C., Gigli, M., Siracusa, V., 2017. An attributional Life Cycle Assessment application experience to highlight environmental hotspots in the production of foamy polylactic acid trays for fresh-food packaging usage. J. Clean. Prod. 150, 93-103.

International Organisation for Standardisation, ISO 14044:2006, 2006. Environmental Management - Life Cycle Assessment - Requirements and Guidelines.

Jain, S., 2019. Global Potential of Biogas. World Gas Association, London.

Krüger, M., Kauertz, B., Detzel, A., 2009. Life Cycle Assessment of Food Packaging Made of Ingeo Biopolymer and (R)PET. IFEU GmbH, Heidelberg.

Leceta, I., Guerrero, P., Cabezudo, S., de la Caba, K., 2013. Environmental assessment of chitosan-based films. J. Clean. Prod. 41, 312-318.

Leceta, I., Etxabide, A., Cabezudo, S., de la Caba, K., Guerrero, P., 2014. Bio-based films prepared with by-products and wastes: environmental assessment. J. Clean. Prod. 64, 218-227.

Lemille, A., Nov 15, 2019. For a True Circular Economy, We Must Redefine Waste. World Economic Forum. Available from: https://www.weforum.org/agenda/ 2019/11/build-circular-economy-stop-recycling/. Accessed 26th February 2020.

Licciardello, F., 2017. Packaging, blessing in disguise. Review on its diverse contribution to food sustainability. Trends Food Sci. Technol. 65, 32-39.

Lorite, G.S., Rocha, J.M., Miilumaki, N., Saavalainen, P., Selkala, T., Morales-Cid, G., Goncalves, M.P., Pongracz, E., Rocha, C.M.R., Toth, G., 2017. Evaluation of physicochemical/microbial properties and life cycle assessment (LCA) of PLA-based nanocomposite active packaging. Food Sci. Technol. 75, 305-315.

Madival, S., Auras, R., Singh, S.P., Narayan, R., 2009. Assessment of the environmental profile of PLA, PET and PS clamshell containers using LCA methodology. J. Clean. Prod. 17 (13), 1183-1194.

Marine Biopolymers, 2013. Seaweed - a hidden treasure. Available from: http:// www.marinebiopolymers.co.uk/. Accessed 30th July 2019.

Massey, S., Pitcairn, J., Minty, N., 2019. Plastics in the Bioeconomy. Ricardo Energy and Environment, Glasgow.

Molina-Besch, K., Wikström, F., Williams, H., 2019. The environmental impact of packaging in food supply chains-does life cycle assessment of food provide the full picture? Int. J. Life Cycle Assess. 24 (1), 37-50.

Muncke, J., 2009. Exposure to endocrine disrupting compounds via the food chain: is packaging a relevant source? Sci. Total Environ. 407 (16), 4549-4559.

Muncke, J., 2015. Food packaging materials. Available from: https://www. foodpackagingforum.org/food-packaging-health/food-packaging-materials. Accessed 30th July 2019.

Napper, I.E., Thompson, R.C., 2019. Environmental deterioration of biodegradable, oxo-biodegradable, compostable, and conventional plastic carrier bags in the sea, soil, and open-air over a 3-year period. Environ. Sci. Technol.

Narancic, T., Verstichel, S., Reddy Chaganti, S., Morales-Gamez, L., Kenny, S.T., De Wilde, B., Babu Padamati, R., O'Connor, K.E., 2018. Biodegradable plastic blends create new possibilities for end-of-life management of plastics but they are not a panacea for plastic pollution. Environ. Sci. Technol. 52 (18), 10441-10452.

Pauer, E., Wohner, B., Heinrich, V., Tacker, M., 2019. Assessing the environmental sustainability of food packaging: an extended life cycle assessment including packaging-related food losses and waste and circularity assessment. Sustainability 11 (3), 925.

Piemonte, V., 2011. Bioplastic wastes: the best final disposition for energy saving. J. Polym. Environ. 19 (4), 988-994. 
Piemonte, V., Gironi, F., 2011. Land-use change emissions: how green are the bioplastics? Environ. Prog. Sustain. Energy 30, 685-691.

Plastics Europe, 2016. Plastics - the Fact 2016. Brussels, Plastics Europe.

Plastics Europe, 2018. Annual Review 2017-2018. Brussels, Plastics Europe.

Posen, I.D., Jaramillo, P., Landis, A.E., Griffin, W.M., 2017. Greenhouse gas mitigation for US plastics production: energy first, feedstocks later. Environ. Res. Lett. 12 (3), 034024

Razza, F., Degli Innocenti, F., 2012. Bioplastics from renewable resources: the benefits of biodegradability. Asia Pac. J. Chem. Eng. 7, S30-S309.

Ross, K., 2019. The Effective Reuse and Applications for Mixed Plastic Waste. Available from: https://www.bpf.co.uk/sustainable_manufacturing/recycling/ Reuse_and_Applications_for_Mixed_Plastic_Waste.aspx. Accessed 8th June 2019.

Rossi, V., Cleeve-Edwards, N., Lundquist, L., Schenker, U., Dubois, C., Humbert, S., Jolliet, O., 2015. Life cycle assessment of end-of-life options for two biodegradable packaging materials: sound application of the European waste hierarchy. J. Clean. Prod. 86, 132-145.

Schweitzer, J., Gionfra, S., Pantzar, M., Mottershead, D., Watkins, E., Petsinaris, F., ten Brink, P., Ptak, E., Lacey, C., Janssens, C., 2018. Unwrapped: How Throwaway Plastic Is Failing to Solve Europe's Food Waste Problem (And what We Need to Do Instead). Institute for European Environmental Policy, Brussels.

Song, J.H., Murphy, R.J., Narayan, R., Davies, G., 2009. Biodegradable and compostable alternatives to conventional plastics. Phil. Trans. Biol. Sci. 364 (1526), 2127-2139.

Spierling, S., Roettger, C., Venkatachalam, V., Mudersbach, M., Herrmann, C., Endres, H., 2018. Bio-based plastics - a building block for the circular economy? In: 25th Cirp Life Cycle Engineering (Lce) Conference, vol. 69, pp. 573-578.

Stein, R.S., 1992. Polymer recycling: opportunities and limitations. Proc. Natl. Acad. Sci. Unit. States Am. 89 (3), 835-838.

Tabone, M.D., Cregg, J.J., Beckman, E.J., Landis, A.E., 2010. Sustainability metrics: life cycle assessment and green design in polymers. Environ. Sci. Technol. 44 (21), 8264-8269.

The Shellworks, 2019. Turning waste lobster shells into bioplastic. Available from: https://www.theshellworks.com/. Accessed 31st July 2019.

The World Bank, 2019. Electric power consumption (kWh per capita). Available from: https://data.worldbank.org/indicator/EG.USE.ELEC.KH.PC. Accessed 14th November 2019.

United Nations, 2015. Transforming Our World: the 2030 Agenda for Sustainable Development (New York, United Nations).

United Nations, 2018. World Urbanization Prospect: the 2018 Revision (United Nations).

U.S. Chamber of Commerce Foundation, 2015. US Achieving a Circular Economy: How the Private Sector Is Reimagining the Future of Business. U.S. Chamber of Commerce Foundation, Washington.
Venkatesh, G., Nyflott, A., Bonnerup, C., Lestelius, M., 2018. An economicenvironmental analysis of selected barrier-coating materials used in packaging food products: a Swedish case study. Environ. Dev. Sustain. 20 (4) 1483-1497.

Verghese, K., Lewis, H., Fitzpatrick, L., 2012. Packaging for Sustainability. Springer Science \& Business Media, London.

Verghese, K., Lewis, H., Lockrey, S., Williams, H., 2013. The Role of Packaging in Minimising Food Waste in the Supply Chain of the Future. RMIT University Report, Melbourne.

Verghese, K., Crossin, E., Clune, S.J., Lockrey, S., Wikström, F., Rio, M., Williams, H., 2014. The greenhouse gas profile of a "Hungry Planet": quantifying the impacts of the weekly food purchases including associated packaging and food waste of three families. In: IAPRI World Conference on Packaging. 19th IAPRI World Conference on Packaging, 15-18 June 2014.

Vidal, R., Martínez, P., Mulet, E., González, R., López-Mesa, B., Fowler, P., Fang, J.M., 2007. Environmental assessment of biodegradable multilayer film derived from carbohydrate polymers. J. Polym. Environ. 15 (3), 159-168.

Wikström, F., Williams, H., 2010. Potential environmental gains from reducing fooc losses through development of new packaging - a life-cycle model. Packag. Technol. Sci. 23 (7), 403-411.

Willett, W., Rockström, J., Loken, B., Springmann, M., Lang, T., Vermeulen, S. Garnett, T., Tilman, D., DeClerck, F., Wood, A., Jonell, M., Clark, M., Gordon, L.J., Fanzo, J., Hawkes, C., Zurayk, R., Rivera, J.A., De Vries, W., Majele Sibanda, L., Afshin, A., Chaudhary, A., Herrero, M., Agustina, R., Branca, F., Lartey, A., Fan, S. Crona, B., Fox, E., Bignet, V., Troell, M., Lindahl, T., Singh, S., Cornell, S.E., Srinath Reddy, K., Narain, S., Nishtar, S., Murray, C.J.L., 2019. Food in the Anthropocene: the EAT-Lancet Commission on Healthy Diets from Sustainable Food Systems.

Williams, H., Wikström, F., 2011. Environmental impact of packaging and fooc losses in a life cycle perspective: a comparative analysis of five food items. J. Clean. Prod. 19 (1), 43-48.

Williams, H., Wikström, F., Löfgren, M., 2008. A life cycle perspective on environmental effects of customer focused packaging development. J. Clean. Prod. 16 (7), 853-859.

World Economic Forum, Ellen MacArthur Foundation \& McKinsey \& Company, 2016. The New Plastics Economy - Rethinking the Future of Plastics. Ellen MacArthur Foundation.

World Economic Forum \& Ellen MacArthur Foundation, 2017. New Plastics Economy: Catalysing Action. Ellen MacArthur Foundation.

WRAP, 2018. Evidence review: Plastic packaging and fresh produce. WRAP, Banbury.

Yates, M.R., Barlow, C.Y., 2013. Life cycle assessments of biodegradable, commercial biopolymers-a critical review. Resour. Conserv. Recycl. 78, 54-66.

Zero Waste Scotland, 2016. How much Food and Drink Waste Is There in Scotland? Stirling, Zero Waste Scotland. 